\title{
A brief review of monolecty in bees and benefits of a broadened definition
}

\author{
James H. CANE \\ emeritus, USDA-ARS, Pollinating Insect Research Unit, Utah State University, Logan, UT 84322-5310, USA
}

Received 14 March 2020 - Revised 13 May 2020 - Accepted 5 June 2020

\begin{abstract}
Monolecty in bees was defined a century ago for those species that consistently collect pollen only from the same single species of floral host. Even at the time, the term was considered "a curiosity" with little biological meaning. Here, I review its multiple problems and suggest that its utility would improve if we apply the term monolecty to those bees species that use a single genus (not species) of flowering host.
\end{abstract}

\section{Anthophila / Oligolecty / Specialization / Pollen}

\section{HISTORY OF TERMINOLOGY}

About a century ago, the bee naturalist Charles Robertson concluded that bee species differed in their pollen foraging predilections. That insight arose from his years of exhaustive bee surveys around his home in Carlinville, Illinois USA, during which he methodically recorded the 441 floral hosts at which he caught 296 bee species (Robertson 1929). Importantly, he recorded foraging behavior as well, which led him to group bee species according to the taxonomic range of plants from which females collected pollen (Robertson 1925). There ensued some lively debate about terminology, causality, and evolution with a contemporary bee enthusiast, John Lovell (1914). Lovell was a keen student of bees and their sometimes-specialized floral associations, but he seemingly failed to appreciate Robertson's key insight in distinguishing between pollen and

Corresponding author: J. CANE,

jim.cane2@gmail.com

This article is part of the Topical Collection on the Apidologie 50 Years

Manuscript editor: James Nieh nectar foraging as regards bee species' floral specializations.

Robertson (1925) divided the spectrum of pollen host use by bees into polylecty (taxonomic generalists) and taxonomic specialization (oligolecty and monolecty). His coinage of oligolecty specifically reserved the term for taxonomic pollen specialization. This usage built upon, but contrasted with, Loew's earlier use of "oligotrophy" which more generally referred to those bee species visiting few flowering species but without regard to the floral resource(s) collected (as cited in Lovell (1918) and Robertson (1925)). The dividing point between polylecty and oligolecty is of course arbitrary and so has engendered endless debate. Subsequent refinements have included "narrow" and "broad" as qualifiers, as well as "mesolecty" as a substitute for "broad oligolecty" (Cane \& Sipes 2007). Robertson's terminology has generally proven useful as shorthand for comparative degrees of pollen host breadth of bee species, helping to focus thinking and discussion about why so many bee species use only small subsets of the potential pollen hosts available to them. 
The least ambiguous category in Robertson's scheme is monolecty. Monolectic bee species use single species of floral host for pollen. Ironically, this most clearly defined term is also the least useful one, as Robertson (1925) himself implied when he judged it to be "rather a curiosity". Both monolecty and floral constancy are evidenced by bee's pure pollen loads drawn from a single pollen host, but monolecty is a fixed and persistent species-specific trait, whereas floral constancy is a labile behavioral trait of individual foragers. Monolecty bounds one end of the spectrum of pollen host use by bee species, which is conceptually useful. In the ensuing decades since Robertson, no more than a few dozen bee species have been found to be monolectic, and even for many of these cases, the designation often requires qualifiers (Table I). Here I assess the utility and meaning of the term in its current usage by reviewing the attributes of the presumptive cases.

\section{PROBLEMS WITH MONOLECTY}

No combination of traits or patterns has been found that unifies the cases of monolecty or even serves to group them in some meaningful scheme. As a result, there is no predictability and therefore no hope for generalizations about monolecty. The cases for monolecty in Table I are drawn from a spectrum of plant and bee families. These families of plants range in size from huge (e.g., $>20,000$ species of Asteraceae and 4600 species of Myrtaceae) to just 100 species (Alismataceae) (Table I). Few plant families are associated with more than a single monolectic bee species. Likewise, all of the major bee families have just one or a few monolectic species (Table I). One to a few monolectic bees are known to inhabit each of the major continents except Asia, whose bee faunas have been less studied (other than those of Japan). Of some predictive value, most of these monolectic bees belong to bee genera with many oligolectic representatives (e.g., Andrena).

A stable designation of monolecty is also particularly susceptible to problems of host plant taxonomy. Classifying bees even as being narrowly oligolectic accommodates the lumping or splitting of a few individual floral host species as new molecular character sets inform taxonomic and phylogenetic treatments. This is untrue of monolecty for two reasons: First, if a monolectic bee species uses both subspecies of a given floral host and these two taxa are later promoted to species status, then the bees lose their status as monoleges. An example from Table I would be the three ploidy races of Larrea tridentata, which if promoted to species status, would negate the current monolectic status of a number of its bees. A related problem is the case of questionable taxonomic splitting of oligolege's floral hosts. Again from Table I, the bee A. astragali actually uses two named but dubious species of Toxicoscordion whose ranges overlap and whose minor defining characters intergrade (Zomlefer 2003). Viewed as one variable floral species, the bee is monolectic, but if the two names are valid, then the bee is narrowly oligolectic. Such instability in application of terminology for floral host use is undesirable.

Many cases of apparent monolecty are merely an artifact of geographically orphaned hosts, for which bees have no opportunity to visit other congeneric flowers. Of the $100+$ bees species that L. tridentata hosts, 22 are specialists for Larrea (Minckley et al. 2000), but because L. tridentata is the sole representative of this amphitropical genus in North America, these are all technically monolectic as well (Table I). Given the chance, would North American Larrea specialists take pollen from the similar-looking flowers of one of the South American species of Larrea? Such a test has been put to the squash bee, Peponapis pruinosa, in its North American range. Its sole native floral host is perennial Cucurbita foetidissima in the American Southwest. During the Holocene, multiple annual squash and pumpkin species were first domesticated in central and South America and then spread into North America. There the bee has adopted them and now prospers on these other cultivated species of Cucurbita (López-Uribe et al. 2016). Contrast this with bees visiting Cistus, one of which, Flavipanurgus venustus, is demonstrably monolectic for one Cistus species (Table I) because it forgoes other co-flowering Cistus species found within its geographic range (Bosch 1992). In general, to know if a bee is monolectic merely for lack of a congeneric pollen host requires 


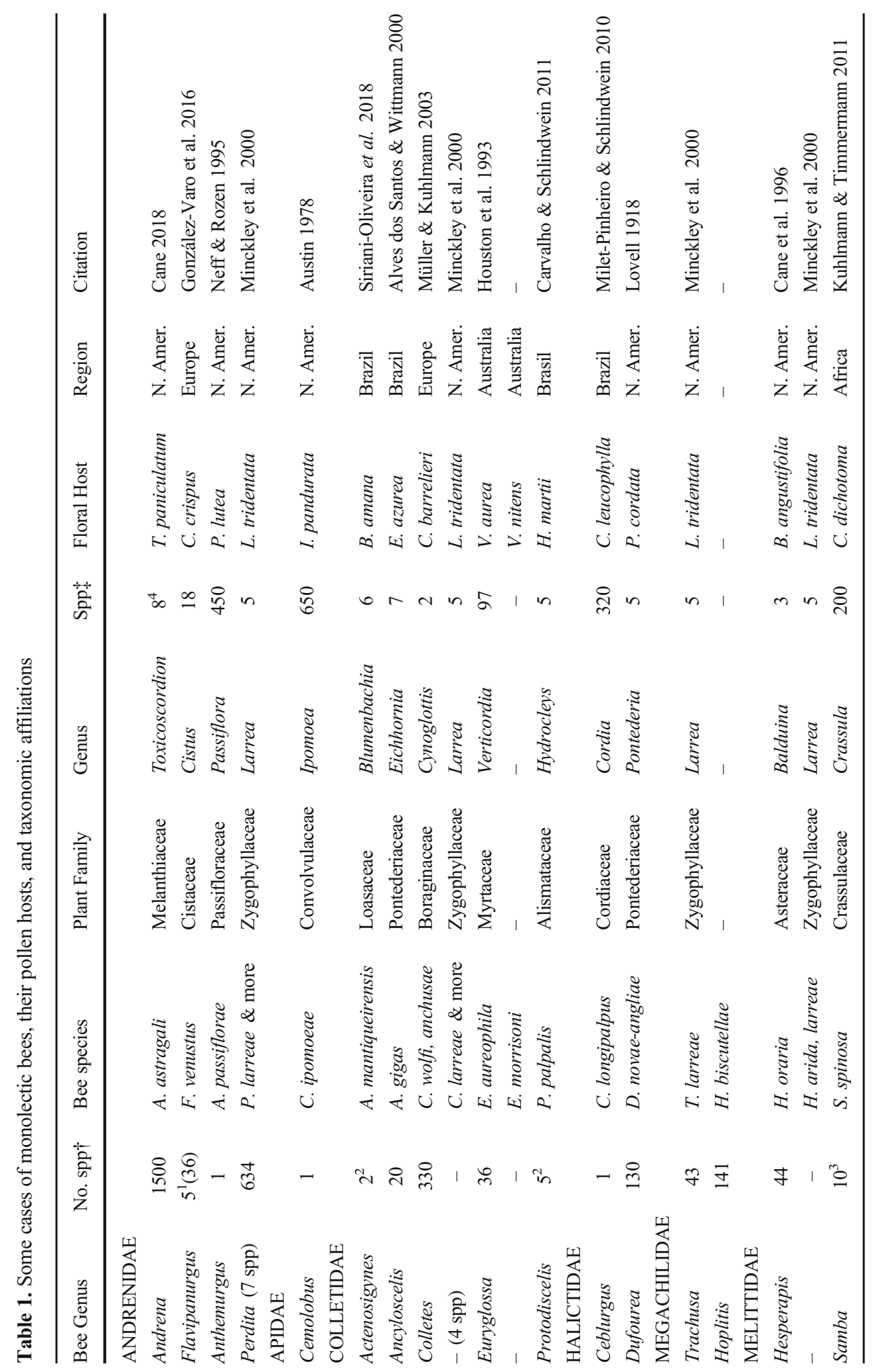


knowing the geographic ranges of both the bee and all other members of the floral host's genus, as well as their seasonal overlap for nesting and flowering.

No predictable pattern accompanies the ecological and floral traits associated with monolecty and its reproductive consequences. Rather than offering any distinct or unifying suite of traits, the handful of cases of monolecty exemplifies the various factors that seem to drive oligolecty in general (Wcislo and Cane 1996; Danforth et al. 2019). Thus, a few of the floral hosts with monoleges represent the "Predictable Plethora" (Wcislo \& Cane 1996) or "superabundant resource" hypotheses (Danforth et al. 2019). In these cases, both specialist and generalist bee species evolutionarily accumulated at the same flowering species because it reliably produces vast quantities of nectar and pollen. Creosote bush (Larrea tridentata) is such a plant (Minckley et al., 2000) being so abundant and widespread that it defines the plant communities of the warm deserts of North America. Some floral hosts of monoleges present flowers bearing easilyaccessible pollen (e.g., Balduina, Cistus, Larrea, Verticordia), but others have hidden pollen requiring specialized behaviors or morphologies for its extraction (Cordia, Cynoglottis ); Ipomoea has overly large pollen that presents transport challenges for some bees (Table I). One case each of monolecty has pollen rewards that are either outright toxic (Toxicoscordion) (Cane, in review) or chemically peculiar (glistening oils covering Verticordia anthers) (Table I). None of these traits is unique to monolecty, as the same causes and consequences are found among multiple cases of narrow oligolecty (Wcislo and Cane 1996; Danforth et al. 2019).

The reproductive consequences of monolecty are also diverse. Some monolectic bees are key pollinators of their floral hosts (e.g., species of Euryglossa, Protodiscelis, Ceblurgus, and Andrena referenced in Table I). Others are inconsequential (Larrea bees, owing to extensive autogamy). At least one monolege is considered an outright pollen thief (Anthemurgus) (references in Table I).

\section{REDEFINING MONOLECTY AND ITS MERITS}

Monolecty as a term could be made less problematic and more useful by a minor change in definition. Monolecty could be redefined as a bee species' taxonomic pollen specialization on members of a single genus of flowering plant. In this way, plant genus would align the taxonomic focus of monolecty with that of oligolecty. So defined, monolecty would still anchor one end of bees' spectrum of floral host specialization. All previous cases of monolecty would still fit, but without any caveats regarding unsettled taxonomy of disputable plant species. Of course, this broadened definition of monolecty would be susceptible to related problems for circumscribing some plant genera. For particularly large plant genera, ones that have been partitioned into subgenera using divergent floral traits (e.g., Penstemon, Ipomoea), perhaps only those bees using a single subgenus should be classified as monolectic (which also anticipates future splitting of the host genus). With the revised definition, many cases now relegated to "narrow oligolecty" would be subsumed under genus-level monolecty. This change would bring together cases of bees that readily collect pollen from multiple congeneric plant species whose flowers seem identical to us (e.g., Salix) and sometimes are not distinguished by their specialist bees either (Cane 2011). As another gain in classification stability, bees first described as monolectic would remain so even when more exhaustive or wide-ranging field surveys reveal an additional congeneric pollen host. This is true retrospectively as well as for future studies. Overall, it seems reasonable to amend a definition that was considered flawed a century ago even by its adopter, Charles Robertson, who himself was amending Loew's 1884 definition of oligotropy. The primary challenge to redefining monolecty as "one bee species using one plant genus for pollen" is adoption of the term, as there is bound to be resistance to change in some quarters and there is no acknowledged authority to render a decision. 


\section{ACKNOWLEDGMENTS}

Clemens Schlindwein and Vincent Tepedino offered insightful criticisms and suggestions, as did an anonymous reviewer.

\section{OPEN ACCESS}

This article is licensed under a Creative Commons Attribution 4.0 International License, which permits use, sharing, adaptation, distribution and reproduction in any medium or format, as long as you give appropriate credit to the original author(s) and the source, provide a link to the Creative Commons licence, and indicate if changes were made. The images or other third party material in this article are included in the article's Creative Commons licence, unless indicated otherwise in a credit line to the material. If material is not included in the article's Creative Commons licence and your intended use is not permitted by statutory regulation or exceeds the permitted use, you will need to obtain permission directly from the copyright holder. To view a copy of this licence, visit http://creativecommons. org/licenses/by/4.0/.

Un bref aperçu de la monolectie chez les abeilles et des avantages d'une définition élargie.

Anthophila / oligolectie / spécialisation / pollen.

Eine kurze übersicht über Monolektie bei Bienen und die Vorteile einer erweiterten Definition.

Anthophila / Oligolektie / Spezializierung / Pollen.

\section{REFERENCES}

Alves dos Santos, I., Wittmann, D. (2000) Legitimate pollination of the tristylous flowers of Eichhornia azurea (Pontederiaceae) by Ancyloscelis gigas bees (Anthophoridae, Apoidea). Plant Syst. Evol. 223, 127-137

Austin, D.F. (1978) Morning glory bees and the Ipomoea pandurata complex (Hymenoptera: Anthophoridae). Proc. Entomol. Soc. Wash. 80, 397-402

Bosch, J. (1992) Floral biology and pollinators of three cooccurring Cistus species (Cistaceae). Bot. J. Linn. Soc. 109, 39-55
Cane, J.H. (2011) Specialist Osmia bees forage indiscriminately among hybridizing Balsamorhiza floral hosts. Oecologia 167, 107-116

Cane, J.H. (2018) Co-dependency between a specialist Andrena bee and its death camas host, Toxicoscordion paniculatum . Arthropod-Plant Interact. 12, 657-662

Cane, J.H., Sipes, S. (2007) Floral specialization by bees: analytical methods and a revised lexicon for oligolecty. In: Waser, N.M. \& Ollerton, J. (eds.). Plant-Pollinator Interactions, pp. 99-122. Univ. Chicago Press, Illinois

Cane, J.H., Snelling, R.R., Kervin, L.J., Eickwort, G.C. (1996) A new monolectic coastal bee, Hesperapis oraria Snelling and Stage (Hymenoptera: Melittidae), with a review of desert and neotropical disjunctives in the southeastern U.S. J. Kans. Entomol. Soc. 69, 238247

Carvalho, A.T., Schlindwein, C. (2011) Obligate association of an oligolectic bee and a seasonal aquatic herb in semi-arid north-eastern Brazil. Biol. J. Linn. Soc. 102, 355-368

Danforth, B.N., Minckley, R.L., Neff, J.L., Fawcett, F. (2019) The Solitary Bees: Biology, Evolution, Conservation. Princeton Univ. Press, Princeton

González-Varo, J.P., Ortiz-Sánchez, F.J., Vilà, M. (2016) Total bee dependence on one flower species despite available congeners of similar floral shape. Plos One, 11 e 0163122

Houston, T.F., Lamont, B.B., Radford, S., Errington, S.G. (1993) Apparent mutualism between Verticordia nitens and V. aurea (Myrtaceae) and their oilingesting bee pollinators (Hymenoptera, Colletidae). Aust. J. Bot. 41 , 369-380

Kuhlmann, M., Timmermann, K. (2011) Nest architecture of the monolectic South African solitary bee, Samba (Prosamba) spinosa Eardley (Hymenoptera: Apoidea: Melittidae). Afr. Entomol. 19, 141-145

López-Uribe, M.M., Cane, J.H., Minckley, R.L., Danforth, B.H. (2016) Crop domestication facilitated rapid geographic expansion of a specialist pollinator, the squash bee. Proc. R. Soc. B Biol. Sci. 283, 20160443

Lovell, J.H. (1914) The origin of oligotropism. Entomol. News 25, 314-321

Lovell, J.H. (1918) The flower and the bee. C. Scribner's \& Sons, New York

Mabberley, D. (2017) Mabberley's Plant-book: A Portable Dictionary of Plants, their Classification and Uses. Cambridge University Press, Cambridge UK

Michener, C.D. (2007) The bees of the world . Johns Hopkins Univ. Press., Baltimore.

Michez, D., Eardley, C., Kuhlmann, M., Timmermann, K., Patiny, S. (2010) The bee genera Haplomelitta and Samba (Hymenoptera : Anthophila : Melittidae): phylogeny, biogeography and host plants. Invertebr. Syst. 24, 327-347

Milet-Pinheiro, P., Schlindwein, C. (2010) Mutual reproductive dependence of distylic Cordia leucocephala (Cordiaceae) and oligolectic Ceblurgus longipalpis 
(Halictidae, Rophitinae) in the Caatinga. Ann. Bot. 106, 17-27

Minckley, R.L., Cane, J.H., Kervin, L. (2000) Origins and ecological consequences of pollen specialization among desert bees. Proc. R. Soc. Lond. B 267, 265-271

Müller, A., Kuhlmann, M. (2003) Narrow flower specialization in two European bee species of the genus Colletes (Hymenoptera : Apoidea : Colletidae). Eur. J. Entomol. 100, 631-635

Neff, J.L., Rozen, J.G. (1995) Foraging and nesting biology of the bee Anthemurgus passiflorae (Hymenoptera: Apoidea), descriptions of its immature stages, and observations on its floral host (Passifloraceae). Am. Mus. Novit. 3138, 19 pp.

Robertson, C. (1925) Heteroptropic bees. Ecology $6412-$ 436

Robertson, C. (1929) Flowers and Insects . Science Press Printing Co., Lancaster.
Siriani-Oliveira, S., Oliveira, R., Schlindwein, C. (2018) Pollination of Blumenbachia amana (Loasaceae): flower morphology and partitioned pollen presentation guarantee a private reward to a specialist pollinator. Biol. J. Linn. Soc. 124, 479-491

Wcislo, W.T., Cane, J.H. (1996) Floral resource utilization by solitary bees (Hymenoptera: Apoidea) and exploitation of their stored foods by natural enemies. Annu. Rev. Entomol. 41, 195-224

Zomlefer, W.B. (2003) Documented chromosome numbers 2003: 1. Chromosome number of Toxicoscordion nuttallii (Liliales: Melanthiaceae) and clarification of the genus. Sida 20, 1085-1092

Publisher's note Springer Nature remains neutral with regard to jurisdictional claims in published maps and institutional affiliations. 